\title{
EFEITO DA CALAGEM SUPERFICIAL EM PLANTIO DIRETO NA CONCENTRAÇÃO DE CÁTIONS HIDROSSOLÚVEIS NA PARTE AÉREA DE CULTURAS ANUAIS ${ }^{(1)}$
}

\author{
Tiago Roque Benetoli da Silva ${ }^{(2)} \&$ Leandro Borges Lemos ${ }^{(3)}$
}

\begin{abstract}
RESUMO
A acidez do solo no sistema plantio direto pode ser minimizada com aplicação superficial de calcário. Tal prática é favorecida pela permanência de restos vegetais na superfície do solo, pela liberação de compostos orgânicos hidrossolúveis, que variam de planta para planta. Por isso foi instalado um experimento em Latossolo Vermelho distrófico (V= 41 \%) em Botucatu (SP), objetivando avaliar os efeitos da aplicação superficial de calcário dolomítico na concentração de cátions solúveis nos resíduos vegetais das culturas de milheto, feijão e aveia preta em dois anos agrícolas (2002/2003 e 2003/2004). No caso do feijoeiro, o delineamento experimental utilizado foi o de blocos casualizados em esquema de parcelas subdivididas, com quatro repetições. As parcelas foram representadas por cultivares de feijão (Carioca, IAC Carioca Eté, Pérola, IAPAR 81 e Campeão 2), enquanto as subparcelas foram formadas por doses de calcário dolomítico (sem aplicação, 1,8; 3,6 e 5,4 t ha-1). Para o milheto e aveia preta foram consideradas apenas as doses como fator. Foram avaliados os teores de $\mathrm{Ca}, \mathrm{Mg}, \mathrm{K}$ e Mn na parte aérea de todas as culturas, bem como a condutividade elétrica no extrato. Os resultados evidenciaram que os teores de $\mathrm{Ca}$, $\mathrm{K}$ e Mg solúveis na parte aérea das culturas anuais avaliadas não foram alterados com a aplicação superficial de doses de calcário dolomítico. As culturas do milheto e feijão apresentaram maior teor de cátions solúveis na parte aérea, quando comparado ao da aveia preta.
\end{abstract}

Termos de indexação: calagem, plantio direto, resíduo vegetal.

\footnotetext{
(1) Parte da Tese de Doutorado do primeiro autor, apresentada à Faculdade de Ciências Agronômicas, Universidade Estadual Paulista - FCA/UNESP. Recebido para publicação em junho de 2007 e aprovado em fevereiro de 2008.

(2) Professor Doutor, Curso de Agronomia, Faculdade Assis Gurgacz - FAG. Avenida das Torres 500, Bairro Santa Cruz, CEP 85806095 Cascavel (PR). E-mail: trbsilva@yahoo.com.br

(3) Professor Dr., Departamento de Produção Vegetal, Faculdade de Ciências Agrárias e Veterinárias, Universidade Estadual Paulista - FCAV/UNESP. Rod. Paulo Donato Castellane s/n, CEP 14884-900 Jaboticabal (SP). E-mail: leandrobl@fcav.unesp.br
} 


\title{
SUMMARY: EFFECT OF SURFACE LIMING OF A SOIL UNDER NO-TILLAGE ON WATER-SOLUBLE CATIONS IN THE SHOOT OF ANNUAL CROPS
}

\begin{abstract}
Soil acidity in no-tillage systems can be amended by surface liming. This practice is favored by plant residues on the soil surface, which release water-soluble organic compounds that vary among plant species. The experiment was conducted on a Typic Hapludox $(V=41 \%)$ in Botucatu, São Paulo State, Brazil, to evaluate the effect of surface liming on the concentration of soluble cations in millet, common bean and black-oat crop residues in two growing seasons (2002/03 and 2003/04). For common bean, a randomized complete block design in split plots with four repetitions was used; the plots were common bean cultivars (Carioca, IAC Carioca Eté, Pérola, IAPAR 81 and Campeão 2) and the subplots were surface application of increasing dolomitic lime rates $\left(0,1.8\right.$; 3.6 e $\left.5.4 t \mathrm{ha}^{-1}\right)$, in October 2002. For millet and black-oat only the rates were considered as studied factors. The concentration of $\mathrm{Ca}, \mathrm{Mg}, \mathrm{K}$, and $\mathrm{Mn}$, and electrical conductivity were analyzed in the shoot. The water-soluble cation concentration in the evaluated crops was not affected by surface application of lime. The water-soluble cation concentration in millet and common bean shoot residues were higher than that of black-oat.
\end{abstract}

Index terms: liming, no-tillage, plant residue.

\section{INTRODUÇÃO}

No sistema plantio direto, intensificou-se o interesse por alternativas para correção da acidez do solo, sem efetuar seu revolvimento. A solução para que não ocorra quebra do sistema plantio direto por meio do preparo de solo convencional é a aplicação superficial de calcário, que resulta em correção de acidez e melhoria de alguns atributos químicos do solo, de acordo com o tempo (Caires et al., 2003).

Esta prática tem-se mostrado positiva ao longo dos anos, como verificado em trabalhos com as culturas da soja (Caires et al., 1998, 2003; Caires \& Fonseca, 2000), do milho (Caires et al., 2002, 2004) e da cevada (Caires et al., 2001).

Tal efeito pode ser explicado pela ação dos fatores químicos, oriundos da reação do solo com fertilizantes nitrogenados, ou seja, as reações do nitrogênio com os elementos oriundos da dissociação do calcário formam sais solúveis, sujeitos à lixiviação pelo movimento descendente da água. Além disso, nota-se a contribuição de fatores biológicos, como a ação da mesofauna, promovendo a mistura entre solo e corretivo e a combinação de ambos os fatores (Moreira, 1999; Vitti \& Luz, 2004).

Além disso, a ausência de revolvimento do solo preconizado pelo sistema plantio direto e a permanência de resíduos vegetais diminuem a velocidade de decomposição de ligantes orgânicos por microrganismos. Tais ligantes podem, com a presença de água, ser solubilizados e lixiviados (Caires, 2000; Miyazawa et al., 2000). Esse fato, somado ao constante aporte de resíduos, possibilita a produção contínua desses compostos orgânicos, podendo resultar em sua manutenção no solo (Amaral et al., 2004). Franchini et al. $(2001,2003)$ observaram que a capacidade dos resíduos vegetais em mobilizar cátions em solos ácidos está relacionada com o teor de ácidos orgânicos de baixo peso molecular.

As plantas de cobertura têm recebido especial atenção graças à liberação destes ácidos orgânicos de baixo peso molecular. Amaral et al. (2004), estudando a aplicação de diferentes resíduos vegetais (ervilhaca, aveia preta e nabo forrageiro) com e sem calcário em superfície, em um Cambissolo Húmico Alumínico léptico argiloso durante cinco anos em plantio direto, concluíram que os resíduos vegetais não tiveram efeito na correção da acidez do solo em profundidade, restringindo-se à camada de $0-2,5 \mathrm{~cm}$, tanto isoladamente como junto com o calcário. Todavia, Miyazawa et al. (1993), avaliando 21 tipos de cobertura vegetal oriunda de adubos verdes, concluíram que todos os materiais vegetais aumentaram o $\mathrm{pH}$ do solo, principalmente os resíduos de leguminosas, com redução do $\mathrm{Al}$ tóxico, em decorrência da complexação orgânica.

Para melhor indicar os efeitos dos resíduos orgânicos na química da solução de solos ácidos, podese fazer uso da somatória de cátions hidrossolúveis (Miyazawa et al., 2002). Dessa forma, a determinação da soma de cátions solúveis pode indicar o potencial de mobilização de cátions e as quantidades de $\mathrm{H}^{+} \mathrm{e}$ $\mathrm{Al}^{3+}$ que podem ser neutralizadas pelos resíduos vegetais, correlacionando-se com os efeitos dos materiais vegetais no aumento do $\mathrm{pH}$ e do Ca trocável 
e na diminuição do $\mathrm{Al}$ trocável do solo (Cassiolato et al., 2002), visto que os cátions $\mathrm{Ca}, \mathrm{Mg}, \mathrm{K}, \mathrm{Na}$ e $\mathrm{Mn}$ ligados nos compostos orgânicos são substituídos por $\mathrm{H}^{+}$ou $\mathrm{Al}^{3+}$, formando compostos estáveis protonados ou complexo Al - orgânico (Miyazawa et al., 2000).

Este trabalho objetivou avaliar os efeitos da aplicação superficial de calcário dolomítico no teor de cátions solúveis nos resíduos vegetais das culturas de milheto, feijão e aveia preta.

\section{MATERIAL E MÉTODOS}

O experimento foi instalado na Fazenda Experimental Lageado, pertencente à Faculdade de Ciências Agronômicas, Campus de Botucatu. As coordenadas geográficas de referência do local do experimento são: latitude sul $22^{\circ} 49^{\prime} 31$ " e longitude oeste $48^{\circ} 25^{\prime} 37^{\prime \prime}$, com altitude de $765 \mathrm{~m}$ e $3 \%$ de declividade. O clima de acordo com a classificação de Köpen é do tipo $\mathrm{Cfa}$, subtropical, com verões quentes e úmidos, invernos frios e secos.

O solo foi classificado, de acordo com Embrapa (1999), como Latossolo Vermelho distrófico, o qual ficou dois anos em pousio; em fevereiro de 2001, foi semeada soja (safrinha) por meio de preparo de solo convencional (uma aração e duas gradagens). Em agosto de 2001, a área experimental foi subsolada e semeou-se guandu, o qual foi manejado com triton e herbicida em 3 de novembro de 2001, permanecendo em pousio até setembro de 2002, sendo, posteriormente, realizado o controle químico de plantas daninhas. Em outubro de 2002, foi feita aplicação do calcário superficialmente, a semeadura do milheto em novembro, iniciando o experimento.

Ao longo dos anos de 2002, 2003 e 2004, utilizou-se a seguinte sucessão de culturas: milheto (primavera) feijão (verão) - aveia preta (outono-inverno), sempre em condições de sequeiro.

O milheto (Cultivar BN-2) foi semeado no dia 06 de novembro de 2002 e, em 18 de outubro de 2003, pelo sistema de plantio direto, no espaçamento de 0,22 m entrelinhas, com $35 \mathrm{~kg} \mathrm{ha}^{-1}$ de sementes. Nos dois anos de experimentação, foram utilizados como adubação de semeadura $100 \mathrm{~kg} \mathrm{ha}^{-1}$ da fórmula 4-20-10.

A semeadura do feijão foi realizada em 19 de dezembro de 2002 e 17 de dezembro de 2003, utilizando $300 \mathrm{~kg} \mathrm{ha}^{-1}$ da fórmula 4-20-10, no primeiro ano, e $280 \mathrm{~kg} \mathrm{ha}^{-1}$ da fórmula 4-14-8, no segundo, como adubação de base e, nos dois anos, $70 \mathrm{~kg} \mathrm{ha}^{-1}$ de nitrogênio em cobertura, utilizando a uréia como fonte. A colheita do primeiro ano foi realizada em 24 de março de 2003 e, no segundo ano, em 12 e 17 de março de 2004.

Posteriormente ao feijão, foram efetuadas as semeaduras da cultura da aveia preta, cultivar
Comum, em 8 de abril de 2003 e, no segundo ano, em 26 de abril de 2004, com espaçamento entrelinhas de $0,17 \mathrm{~m}$, utilizando-se $45 \mathrm{~kg} \mathrm{ha}^{-1}$ de sementes. Foram utilizados como adubação de semeadura $150 \mathrm{~kg} \mathrm{ha}^{-1}$ da fórmula 10-20-10, em 2003, e no segundo ano de experimentação, $200 \mathrm{~kg} \mathrm{ha}^{-1}$ da fórmula 4-20-10.

Coletaram-se amostras de solo antes da aplicação de calcário, nas profundidades de $0-5 ; 5-10 ; 10-20$ e 20-40 cm, realizando-se análise química de rotina e do teor de $\mathrm{Al}$, visando caracterizar o solo da área experimental, obtendo-se, como média, saturação por bases $(\mathrm{V})$ de $41 \%$ e CTC $=98,5 \mathrm{mmol}_{\mathrm{c}} \mathrm{dm}^{-3}$, as quais foram utilizadas para o cálculo da necessidade de calcário.

O calcário foi aplicado manualmente em 15 de outubro de 2002 , apresentando $72 \%$ de poder relativo de neutralização total (PRNT), com 84,3\% de poder de neutralização $(\mathrm{PN}), 84,5 \%$ de reatividade (RE), $23,3 \%$ de $\mathrm{CaO}$ e $17,5 \%$ de $\mathrm{MgO}$.

$\mathrm{Na}$ análise dos dados provenientes do feijoeiro, o delineamento experimental utilizado foi o de blocos casualizados disposto em um esquema de parcelas subdivididas. Os tratamentos foram constituídos pela combinação de diferentes cultivares de feijão (C1 Carioca; C2 - IAC Carioca Eté; C3 - Pérola; C4 IAPAR 81 e C5 - Campeão 2) e as subparcelas formadas pelas doses de calcário dolomítico (D0 =zero - sem aplicação de calcário; D1 = 1,8 t ha ${ }^{-1}$ - quantidade de calcário para elevar a saturação por bases a $54 \%$; D2 $=3,6 \mathrm{t} \mathrm{ha}^{-1}$ - quantidade de calcário para elevar a saturação por bases a $68 \%$ e D3 $=5,4$ t ha $^{-1}$ quantidade de calcário para elevar a saturação por bases a $80 \%$ ), totalizando 20 tratamentos, com quatro repetições. As subparcelas foram constituídas por 10 linhas de seis metros de comprimento, considerando como área útil as oito linhas centrais. Foi desprezado 0,5 $\mathrm{m}$ em ambas as extremidades de cada linha, nos dois anos de experimentação.

$\mathrm{Na}$ análise dos dados do milheto e da aveia preta foi utilizado o delineamento experimental de blocos ao acaso, considerando apenas as doses de calcário como fator, totalizando 16 parcelas, espaçadas entre si em um metro. Cada parcela foi formada por 20 linhas com $6 \mathrm{~m}$ de comprimento, espaçada em 0,22 m. Como área útil de cada parcela, foram consideradas as 18 linhas centrais, desprezando-se $0,5 \mathrm{~m}$ de cada extremidade.

No florescimento de cada cultura (feijão e aveia preta) e aos 45 dias da emergência das plantas de milheto (época em que o solo foi manejado quimicamente para semeadura do feijoeiro), realizou-se a coleta da parte aérea das plantas contidas em $2 \mathrm{~m}$ de fileira, em cada subparcela, no caso da cultura do feijão, e em cada parcela, no caso da cultura do milheto e aveia preta (nos dois anos agrícolas). As plantas foram cortadas rente ao solo e acondicionadas em sacos de papel devidamente identificados, os quais foram 
levados para secagem em estufa de ventilação forçada à temperatura de $65^{\circ} \mathrm{C}$, até atingirem peso constante. Em seguida, as plantas foram moídas, passadas em peneira de 1,0 mm e armazenadas em sacos plásticos, para posterior avaliação da qualidade do resíduo vegetal, segundo método descrito por Miyazawa et al. (2000) e Meda et al. (2002).

Para extração dos compostos hidrossolúveis (ácidos orgânicos de baixo peso molecular), transferiu-se $1 \mathrm{~g}$ dos resíduos para frascos de $100 \mathrm{~mL}$ e foram adicionados $50 \mathrm{~mL}$ de água destilada, agitando-se por quatro horas, com posterior filtragem em papel-filtro qualitativo de filtragem rápida. De posse dos extratos vegetais, os teores de $\mathrm{Ca}, \mathrm{Mg}, \mathrm{K}$ e $\mathrm{Mn}$ foram determinados por espectrometria de emissão ótica com plasma acoplado indutivamente (ICP-OES). Os resultados foram expressos em $\mathrm{mmol}_{\mathrm{c}} \mathrm{kg}^{-1}$, de forma individual para cada elemento e na forma de soma de cátions ( $\Sigma \mathrm{Ca}, \mathrm{Mg}, \mathrm{K}$ e Mn). A soma de cátions solúveis constitui as quantidades de $\mathrm{H}^{+}{\mathrm{e} \mathrm{Al}^{3+}}^{3+}$ que podem ser neutralizadas pelo resíduo vegetal (Miyazawa et al., 2000). Foi também determinada, no extrato vegetal, a condutividade elétrica da solução por condutivimetria, em $\mu \mathrm{S} \mathrm{cm}^{-1}$, de acordo com a proposta de Miyazawa et al. (2000).
Foi realizada análise de variância para todos os dados, no caso do feijoeiro, para os cultivares, realizouse teste de Tukey ( $5 \%$ de probabilidade) como comparação das médias, para as doses, foi efetuada análise de regressão polinomial. Para o milheto e aveia preta, foram consideradas as doses de calcário como fator, utilizando a regressão polinomial.

\section{RESULTADOS E DISCUSSÃO}

Como pode ser observado na figura 1, não foram verificadas diferenças nos teores de cátions solúveis, somatória e condutividade elétrica, nos dois anos de experimentação, para a cultura do milheto. Pode-se notar, porém, que, no primeiro ano (2002), os teores de $\mathrm{Ca}, \mathrm{K}$ e $\mathrm{Mg}$ foram maiores que os do segundo ano (2003), uma vez que as plantas tiveram seu crescimento retardado em razão dos baixos índices pluviométricos e, de acordo com Malavolta et al. (1997) e Epstein \& Bloom (2006), com ausência de água ocorre, conseqüentemente, menor absorção de nutrientes.

Como a soma de cátions foi maior no primeiro ano, esperava-se que a condutividade elétrica seguisse esse
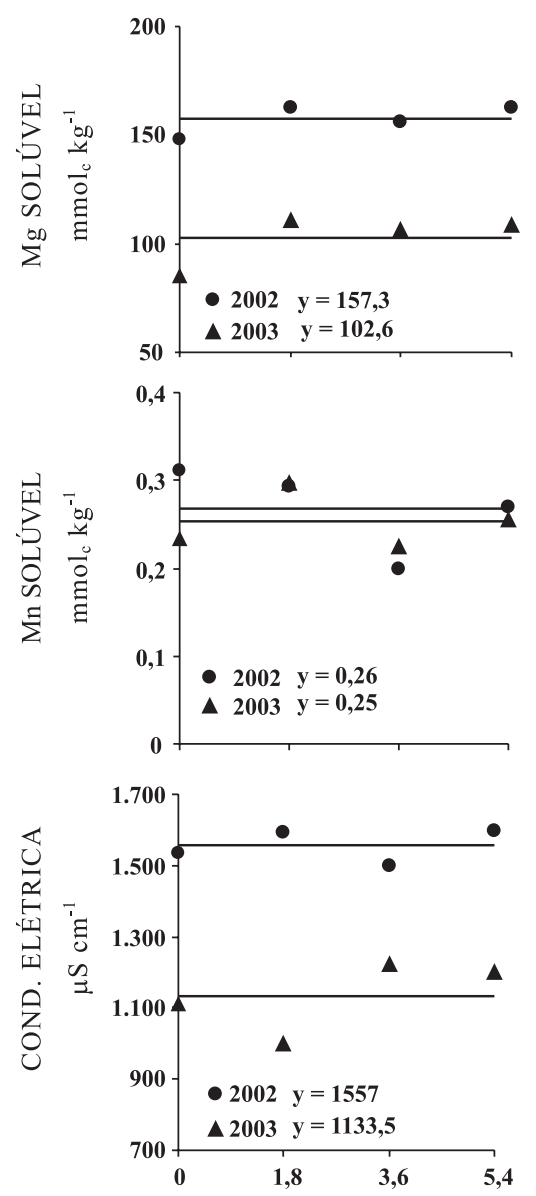

Figura 1. Teores de cátions hidrossolúveis nos resíduos vegetais de milheto, aferidos na época do florescimento e condutividade elétrica do extrato. 
mesmo padrão, haja vista maior quantidade de sais solúveis no extrato (Miyazawa et al., 2000). No entanto, isso não foi verificado, uma vez que a quantidade de sais não foi suficiente para alteração significativa na condutividade elétrica.

Para a cultura do feijão, no primeiro ano do experimento, verificou-se diferença significativa entre os cultivares, para o teor de Mn e soma de bases (Quadro 1). IAC Carioca Eté apresentou teor de $\mathrm{Mn}^{2+}$ maior em comparação ao do cultivar Pérola. Esta maior quantidade de Mn solúvel não resultou em maior soma de base. Isso discorda de Cassiolato et al. (2000) que verificaram diferenças nos teores de cátions solúveis entre plantas do mesmo gênero vegetal (aveia preta e aveia branca). Soratto \& Crusciol (2007) também encontraram diferenças entre cultivares de arroz e feijão.
Ainda pelo quadro 2, não se observou diferença significativa nos teores de bases entre os cultivares de feijão, o que discorda dos resultados encontrados pelos autores supracitados.

A aplicação de doses de calcário dolomítico não proporcionou elevação nos teores de cátions solúveis na parte aérea do feijoeiro, tampouco alterações significativas na condutividade elétrica, nos dois anos de experimentação (Figura 2). Pode-se observar que, em média, no segundo ano, os teores de Ca e Mg foram maiores que no primeiro ano, demonstrando que o corretivo demorou mais para reagir no solo. Segundo Rheinheimer et al. (2000), Amaral \& Anghinoni (2001), Ciota et al. (2004) e Vitti \& Luz (2004), a aplicação superficial de corretivos de acidez leva tempo maior para reação no solo, quando comparado com métodos convencionais de aplicação. Isso também fica

Quadro 1. Teores de cátions hidrossolúveis nos resíduos vegetais da primeira safra de cultivares de feijão, aferidos na época do florescimento e condutividade elétrica do extrato

\begin{tabular}{|c|c|c|c|c|c|c|}
\hline \multirow{2}{*}{ Tratamento } & \multicolumn{5}{|c|}{ Cátion solúvel } & \multirow{2}{*}{$\begin{array}{c}\text { Condutividade } \\
\text { elétrica }\end{array}$} \\
\hline & $\mathrm{Ca}^{2+}$ & $\mathbf{M g}^{2+}$ & $\mathbf{K}^{+}$ & $\mathbf{M n}^{2+}$ & $\Sigma^{(1)}$ & \\
\hline Cultivar & \multicolumn{5}{|c|}{$-\mathrm{mmol}_{\mathrm{c}} \mathrm{kg}^{-3}$} & $\mu \mathrm{S} \mathrm{cm}^{-1}$ \\
\hline Carioca & $250,0 \mathrm{a}$ & $127,1 \mathrm{a}$ & $589,7 \mathrm{a}$ & $7,7 \mathrm{ab}$ & 974,5 a & $1.680 \mathrm{a}$ \\
\hline IAC Carioca Eté & $275,0 \mathrm{a}$ & $131,3 \mathrm{a}$ & $589,7 \mathrm{a}$ & $8,1 \mathrm{a}$ & $1004,1 \mathrm{a}$ & $1.698 \mathrm{a}$ \\
\hline Pérola & 250,0 a & $135,4 \mathrm{a}$ & $487,2 \mathrm{a}$ & $6,9 \mathrm{~b}$ & 879,5 a & $1.654 \mathrm{a}$ \\
\hline IAPAR 81 & $250,0 \mathrm{a}$ & $131,3 \mathrm{a}$ & $589,7 \mathrm{a}$ & $7,1 \mathrm{ab}$ & $978,1 \mathrm{a}$ & $1.659 \mathrm{a}$ \\
\hline Campeão 2 & $250,0 \mathrm{a}$ & $141,7 \mathrm{a}$ & $512,8 \mathrm{a}$ & $7,3 \mathrm{ab}$ & $911,7 \mathrm{a}$ & $1.677 \mathrm{a}$ \\
\hline $\mathrm{CV}_{1}(\%)$ & 11,1 & 17,6 & 26,4 & 14,1 & 15,4 & 11,1 \\
\hline $\mathrm{CV}_{2}(\%)$ & 9,8 & 13,2 & 24,1 & 12,8 & 11,2 & 9,8 \\
\hline
\end{tabular}

(1) Somatório. Médias seguidas de mesma letra, na coluna, dentro de cada fator, não diferem entre si pelo teste de tukey a $5 \%$. $\mathrm{CV}_{1}$ : coeficiente de variação das parcelas. $\mathrm{CV}_{2}$ : coeficiente de variação das subparcelas.

Quadro 2. Teores de cátions hidrossolúveis nos resíduos vegetais da segunda safra de cultivares de feijão, aferidos na época do florescimento e condutividade elétrica do extrato

\begin{tabular}{|c|c|c|c|c|c|c|}
\hline \multirow{2}{*}{ Tratamento } & \multicolumn{5}{|c|}{ Cátion solúvel } & \multirow{2}{*}{$\begin{array}{c}\text { Condutividade } \\
\text { elétrica }\end{array}$} \\
\hline & $\mathrm{Ca}^{2+}$ & $\mathbf{M g}^{2+}$ & $\mathbf{K}^{+}$ & $\mathrm{Mn}^{2+}$ & $\sum^{(1)}$ & \\
\hline Cultivar & \multicolumn{5}{|c|}{$\operatorname{mmol}_{\mathrm{c}} \mathrm{kg}^{-3}$} & $\mu \mathrm{S} \mathrm{cm}^{-1}$ \\
\hline Carioca & $393,8 \mathrm{a}$ & $141,7 \mathrm{a}$ & $410,3 \mathrm{a}$ & $1,3 \mathrm{a}$ & $947,0 \mathrm{a}$ & $1.654 \mathrm{a}$ \\
\hline IAC Carioca Eté & $418,8 \mathrm{a}$ & $154,2 \mathrm{a}$ & $461,5 \mathrm{a}$ & $1,6 \mathrm{a}$ & $1036,1 \mathrm{a}$ & $1.662 \mathrm{a}$ \\
\hline Pérola & $358,8 \mathrm{a}$ & $162,5 \mathrm{a}$ & 384,6 a & $1,2 \mathrm{a}$ & $907,1 \mathrm{a}$ & $1.601 \mathrm{a}$ \\
\hline IAPAR 81 & $350,0 \mathrm{a}$ & $147,9 \mathrm{a}$ & $461,5 \mathrm{a}$ & $1,3 \mathrm{a}$ & $960,8 \mathrm{a}$ & $1.645 \mathrm{a}$ \\
\hline Campeão 2 & 356,3 a & $152,1 \mathrm{a}$ & 435,9 a & $1,7 \mathrm{a}$ & $945,9 \mathrm{a}$ & $1.659 \mathrm{a}$ \\
\hline $\mathrm{CV}_{1}(\%)$ & 19,1 & 16,8 & 23,2 & 38,6 & 25,5 & 14,3 \\
\hline $\mathrm{CV}_{2}(\%)$ & 11,1 & 11,8 & 20,5 & 39,5 & 23,4 & 13,2 \\
\hline
\end{tabular}

(1) Somatório. Médias seguidas de mesma letra, na coluna, dentro de cada fator, não diferem entre si pelo teste de tukey a 5 \%. $\mathrm{CV}_{1}$ : coeficiente de variação das parcelas. $\mathrm{CV}_{2}$ : coeficiente de variação das subparcelas. 
evidenciado pela diminuição do teor de Mn do primeiro ano para o segundo, uma vez que corretivos de acidez neutralizam acidez de solo, tornando alguns elementos indisponíveis às plantas, sendo o Mn um deles (Quaggio, 2000; Alcarde \& Rodella, 2003; Vitti \& Luz, 2004).

A aplicação de doses de calcário não alterou de forma significativa os cátions solúveis e condutividade elétrica nos extratos do resíduo da aveia preta (Figura 3). Observaram-se, ainda, valores muito próximos para condutividade elétrica, quando comparados os dois anos de experimentação.

O efeito das doses de calcário não foi pronunciado quanto à concentração de cátions solúveis na parte aérea das culturas do milheto, feijão e aveia preta. Gatiboni et al. (2003) verificaram alterações significativas nos atributos químicos do solo em profundidade após 84 meses da aplicação superficial de calcário. Caires et al. (1998) verificaram efeito da aplicação superficial de calcário em um Latossolo Vermelho, apenas na camada de $0-10 \mathrm{~cm}$ após 12 meses da aplicação, ficando mais pronunciado após 24 meses. Isso demonstra que, em certos experimentos, ficam constatadas modificações no solo sem alteração nos teores de cátions na parte aérea das culturas (Caires et al., 2003).

Outros resultados demonstram contraste no efeito do resíduo vegetal nos atributos químicos do solo, como Amaral et al. (2004) verificaram em seu experimento que os resíduos vegetais não causaram efeito na correção da acidez de solo em profundidade, restringindo-se a um efeito apenas nos primeiros $2,5 \mathrm{~cm}$ de solo, tanto isoladamente quanto junto com o calcário. Já Crusciol et al. (2003) e Soratto \& Crusciol (2007) observaram diferenças nos teores foliares de algumas culturas anuais de acordo com a aplicação de calcário. Tais modificações ocorreram de forma gradual e progressiva a partir da superfície do solo, afetando tanto a disponibilidade de nutrientes quanto o processo de acidificação do solo (Amaral \& Anghinoni, 2001).

De modo geral, os resíduos da cultura do feijão mostraram, em média, maior teor de Ca solúvel (Quadro 3), apresentando cerca de 2,5 vezes mais do que o milheto. Soratto \& Crusciol (2007) verificaram maior teor de Ca na parte aérea do feijão, quando
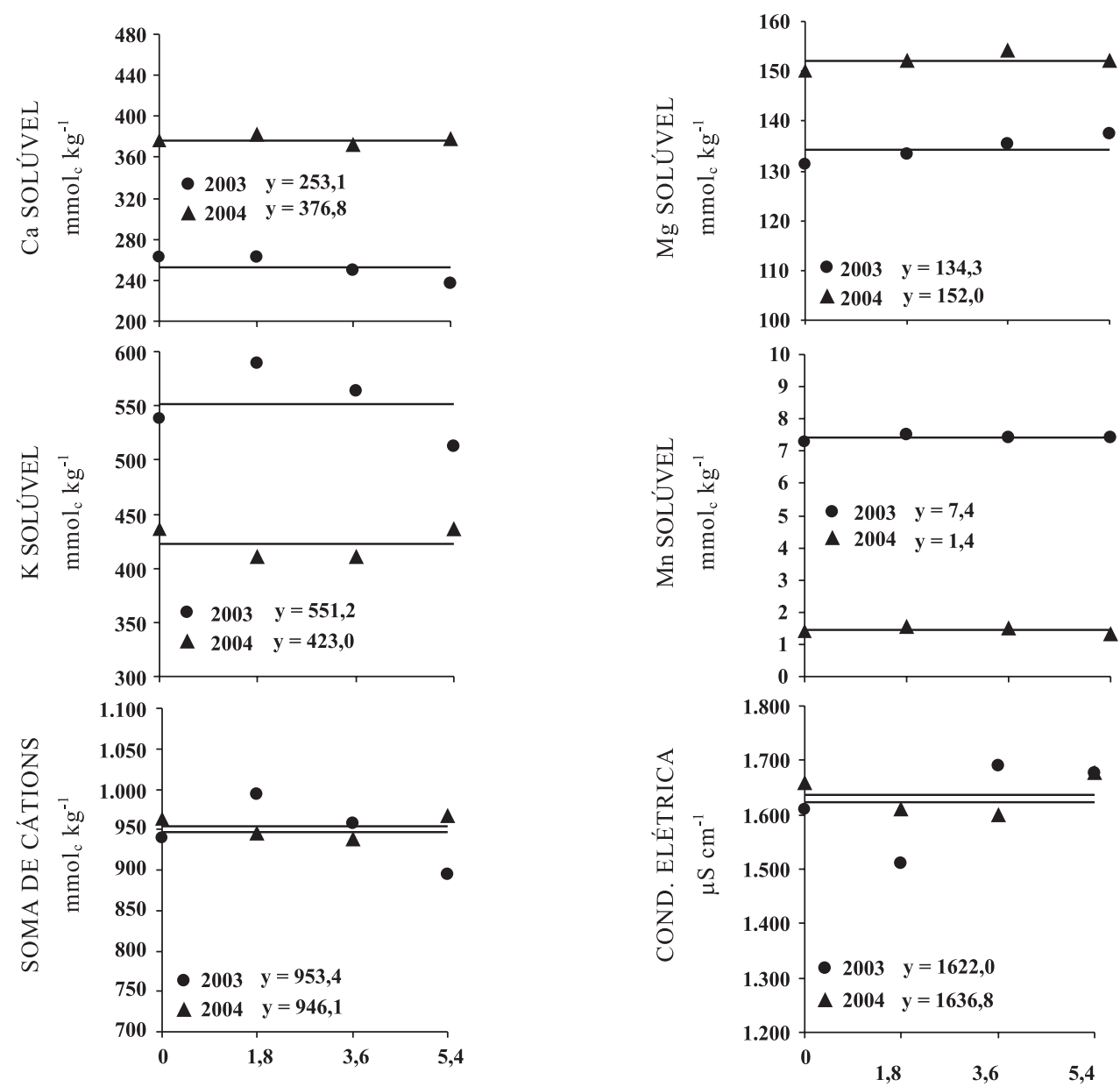

Figura 2. Teores de cátions hidrossolúveis nos resíduos vegetais de feijão, aferidos na época do florescimento e condutividade elétrica do extrato. 
comparado com restos vegetais do arroz e aveia preta. A aveia preta apresentou menor teor de Ca solúvel. Há grande variabilidade entre as espécies quanto à solubilidade dos cátions, sobretudo do Ca (Quadro 3), como já havia sido observado por Franchini et al. (2001) e Meda et al. (2001, 2002).
Quanto aos teores de Mg solúvel, verificou-se no resíduo do feijoeiro valor bem semelhante ao do milheto, porém maior que da aveia preta (Quadro 3). $\mathrm{O}$ milheto apresentou maior teor de $\mathrm{K}$ solúvel, já o teor de Mn solúvel foi maior no feijoeiro quando comparado com as outras culturas, discordando dos

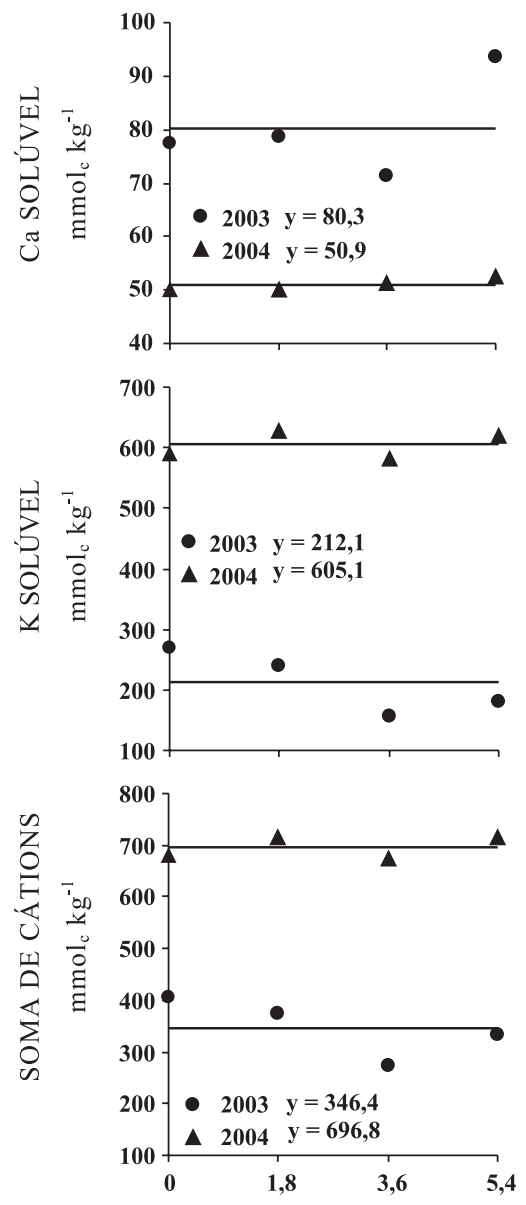

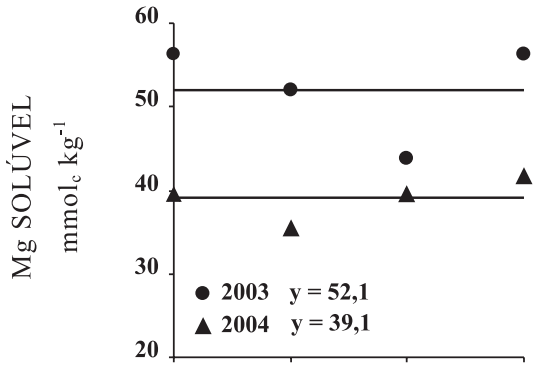
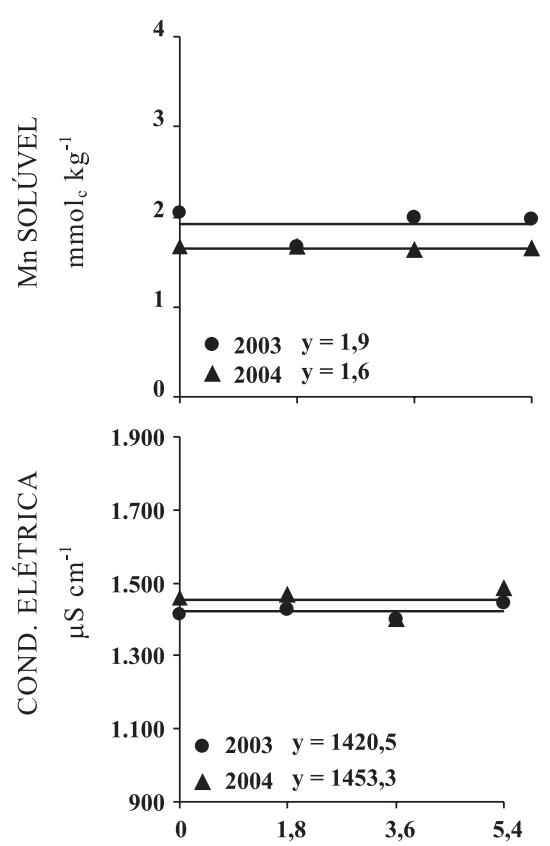

Figura 3. Teores de cátions hidrossolúveis nos resíduos vegetais de aveia preta, aferidos na época do florescimento e condutividade elétrica do extrato.

Quadro 3. Teores de cátions hidrossolúveis nos resíduos vegetais da segunda safra de cultivares de feijão, aferidos na época do florescimento e condutividade elétrica do extrato

\begin{tabular}{|c|c|c|c|c|c|c|}
\hline \multirow[b]{2}{*}{ Cultura } & \multicolumn{5}{|c|}{ Cátion solúvel } & \multirow{2}{*}{$\begin{array}{c}\text { Condutividade } \\
\text { elétrica }\end{array}$} \\
\hline & $\mathrm{Ca}^{2+}$ & $\mathrm{Mg}^{2+}$ & $\mathbf{K}^{+}$ & $\mathbf{M n}^{2+}$ & $\Sigma^{(1)}$ & \\
\hline & \multicolumn{5}{|c|}{$-\mathrm{mmol}_{\mathrm{c}} \mathrm{kg}^{-3}$} & $\mu \mathrm{S} \mathrm{cm}^{-1}$ \\
\hline Milheto $^{(2)}$ & 134,1 & 129,9 & 749,3 & 0,26 & $1.013,6$ & 1.345 \\
\hline Feijão ${ }^{(2)}$ & 315,0 & 143,2 & 487,1 & 4,42 & 949,8 & 1.629 \\
\hline Aveia preta ${ }^{(2)}$ & 65,6 & 45,5 & 408,6 & 1,78 & 521,6 & 1.436 \\
\hline
\end{tabular}

(1) Somatório. ${ }^{(2)}$ Média de dois anos. 
resultados encontrados por Soratto \& Crusciol (2007), que encontraram nos restos vegetais do feijoeiro o menor teor de Mn.

Os resíduos vegetais das culturas apresentaram a seguinte ordem decrescente de cátions solúveis nos extratos dos resíduos vegetais: $\mathrm{K}>\mathrm{Ca}>\mathrm{Mg}>\mathrm{Mn}$, o que discorda do relatado por Meda et al. (2002), para extratos de plantas invasoras, e dos resultados de Soratto \& Crusciol (2007). A solubilidade maior do K, é explicada, possivelmente pela sua mobilidade dentro da planta, sendo altamente móvel no floema, formando ligações de fácil reversibilidade (Malavolta et al., 1997; Epstein \& Bloom, 2006).

Quanto à soma de cátions solúveis, as culturas do feijão e milheto apresentaram valores maiores e bem próximos, quando comparados aos da aveia preta. A condutividade elétrica dos extratos vegetais indicou a concentração dos íons dissolvidos na solução, podendo os valores correlacionar-se positivamente com a determinação da soma de cátions (Miyazawa et al., 2000). Observou-se que o extrato dos resíduos vegetais do feijoeiro teve maior condutividade elétrica, quando comparado com o milheto, mesmo este apresentando maior soma de cátions solúveis. Isso pode ser explicado porque, no segundo ano, a cultura do milheto mostrou menores valores de soma de bases, acarretando baixa condutividade elétrica, o que diminuiu a média, quando utilizado em dois anos.

\section{CONCLUSÕES}

1. Os teores de $\mathrm{Ca}, \mathrm{K}$ e $\mathrm{Mg}$ solúveis na parte aérea das culturas anuais avaliadas não foram alterados com a aplicação superficial de doses de calcário dolomítico.

2. As culturas do milheto e feijão apresentaram maior teor de cátions solúveis na parte aérea, quando comparado ao da aveia preta.

\section{AGRADECIMENTO}

\section{À FAPESP, pelo apoio financeiro.}

\section{LITERATURA CITADA}

ALCARDE, J.C. \& RODELLA, A.A. Qualidade e legislação de fertilizantes e corretivos. In: CURI, N.; MARQUES, J.J.; GUILHERME, L.R.G.; LIMA, J.M.; LOPES, A.S. \& ALVAREZ V., V.H., eds.Tópicos em ciência do solo. Viçosa, MG, Sociedade Brasileira de Ciência do Solo, 2003. v.3. p.291-334.

AMARAL, A.S. \& ANGHINONI, I. Alteração de parâmetros químicos do solo pela reaplicação superficial de calcário no sistema plantio direto. Pesq. Agropec. Bras., 36:936 941, 2001.
AMARAL, A.S.; ANGHINONI, I. \& DESCHAMPS, F.C. Resíduos de plantas de cobertura e mobilidade dos produtos da dissolução do calcário aplicado na superfície. R. Bras. Ci. Solo, 28:115-123, 2004.

CAIRES, E.F. \& FONSECA, A.F. Absorção de nutrientes pela soja cultivada no sistema de plantio direto em função de calagem na superfície. Bragantia, 59:213-220, 2000.

CAIRES, E.F. Manejo da fertilidade do solo no sistema plantio direto: Experiências no Estado do Paraná. In: REUNIÃO BRASILEIRA DE FERTILIDADE DO SOLO E NUTRIÇÃO DE PLANTAS, 25., Santa Maria, 2000. Anais. Santa Maria, Sociedade Brasileira de Ciência do Solo, 2000. 28p. CD-ROM.

CAIRES, E.F.; BARTH, G.; GARBUIU, F.J. \& KUSMAN, M.T. Correção da acidez do solo, crescimento radicular e nutrição do milho de acordo com a calagem na superfície em sistema plantio direto. R. Bras. Ci. Solo, 25:1011-1022, 2002 .

CAIRES, E.F.; BLUM, J.; BARTH, G.; GARBUIU, F.J. \& KUSMAN, M.T. Alterações químicas do solo e resposta da soja ao calcário e gesso aplicados na implantação do sistema plantio direto. R. Bras. Ci. Solo, 27:275-286, 2003.

CAIRES, E.F.; CHUEIRI, W.A.; MADRUGA, E.F. \& FIGUEIREDO, A. Alterações de características químicas do solo e resposta da soja ao calcário e gesso aplicados na superfície em sistema de cultivo sem preparo de solo. R. Bras. Ci. Solo, 22:27-34, 1998.

CAIRES, E.F.; FELDHAUS, I.C. \& BLUM, J. Crescimento radicular e nutrição da cevada em função da calagem e aplicação de gesso. Bragantia, 60:213-223, 2001.

CAIRES, E.F.; KUSMAN, M.T.; BARTH, G.; GARBUIU, F.J. \& PADILHA, J.M. Alterações químicas do solo e resposta do milho à calagem e aplicação de gesso. R. Bras. Ci. Solo, 28:125-136, 2004

CASSIOLATO, M.E.; MEDA, A.R.; PAVAN, M.A.; MIYAZAWA, M. \& OLIVEIRA, J.C. Evaluation of oat extracts on the efficiency of lime in soil. Braz. Arch. Biol. Technol., 43:533536, 2000.

CASSIOLATO, M.E.; MIYAZAWA, M.; MEDA, A.R. \& PAVAN, M.A. A laboratory method to estimate the efficiency of plant extract to neutralize soil acidity. Braz. Arch. Biol. Technol., 45:183-187, 2002.

CIOTA, M.N.; BAYER, C.; ERNANI, P.R.; FONTOURA, S.M.V.; WOBETO, C. \& AlBUQUERQUE, J.A. Manejo da calagem e os componentes da acidez de Latossolo Bruno em plantio direto. R. Bras. Ci. Solo, 28:317-326, 2004.

CRUSCIOL, C.A.C.; LAZARINI, E. \& SORATTO, R.P. Efeito da aplicação de calcário no sulco de semeadura sobre a nutrição e produtividade de amendoim semeado em diferentes épocas no cultivo da seca. Científica, 31:201209, 2003

EPSTEIN, E. \& BLOOM, A.J. Nutrição mineral de plantas: Princípios e perspectivas. 2.ed. Londrina, Planta, 2006. 403p.

FRANCHINI, J.C.; HOFFMANN-CAMPO, C.B.; TORRES, E.; MIYAZAWA, M. \& PAVAN, M.A. Organic composition of green manures during growth and its effect on cation mobilization in an acid Oxisol. Comm. Soil Sci. Plant Anal., 34:2045-2058, 2003. 
FRANCHINI, J.C.; MEDA, A.R.; CASSIOLATO, M.E.; MIYAZAWA, M. \& PAVAN, M.A. Potencial de extratos de resíduos vegetais na mobilização do calcário no solo por métodos biológicos. Sci. Agric., 58:357-360, 2001.

GATIBONI, L.C.; SAGGIN, A.; BRUNETTO, G.; HORN, D.; FLORES, J.P.C.; RHEINHEIMER, D.S. \& KAMINSKI, J. Alterações dos atributos químicos de solo arenoso pela calagem superficial no sistema plantio direto consolidado. Ci. Rural, 33:283-290, 2003.

MALAVOLTA, E.; VITTI, G.C. \& OLIVEIRA, S.A. Avaliação do estado nutricional de plantas: Princípios e aplicações. 2.ed. Piracicaba, Potafos, 1997. 319p.

MEDA, A.R.; CASSIOLATO, M.E.; PAVAN, M.A. \& MIYAZAWA, M. Alleviating soil acidity through plant organic compounds. Braz. Arch. Biol. Technol., 44:185189, 2001

MEDA, A.R.; PAVAN, M.A.; MIYAZAWA, M. \& CASSIOLATO, M.E. Plantas invasoras para melhorar a eficiência da calagem na correção da acidez subsuperficial do solo. $\mathrm{R}$. Bras. Ci. Solo, 26:647-654, 2002.

MIYAZAWA, M.; PAVAN, M.A. \& CALEGARI, A. Efeito de material vegetal na acidez do solo. R. Bras. Ci. Solo, 17:411416,1993
MIYAZAWA, M.; PAVAN, M.A. \& FRANCHINI, J.C. Evaluation of plant residues on the mobility os surface applied lime. Braz. Arch. Biol. Technol., 45:251-256, 2002.

MIYAZAWA, M.; PAVAN, M.A. \& FRANCHINI, J.C. Neutralização da acidez do perfil do solo por resíduos vegetais. Inf. Agron., 92:8, 2000. (Encarte Técnico)

MOREIRA, S.G. Calagem em sistema de semeadura direta e efeitos sobre a acidez do solo, disponibilidade de nutrientes e produção da soja. Piracicaba, Escola Superior de Agricultura “Luiz de Queiroz", 1999. 87p. (Tese de Mestrado)

QUAGGIO, J.A. Acidez e calagem em solos tropicais. Campinas, Instituto Agronômico de Campinas, 2000. 111p.

RHEINHEIMER, D.S.; SANTOS, E.J.S.; KAMINSKI, J. \& XAVIER, F.M. Aplicação superficial de calcário no sistema plantio direto consolidado em solo arenoso. Ci. Rural, 30:263-268, 2000 .

SORATTO, R.P. \& CRUSCIOL, C.A.C. Cátions hidrossolúveis na parte aérea de culturas anuais mediante aplicação de calcário e gesso em superfície. R. Bras. Ci. Solo, 31:81-90, 2007.

VITTI, G.C. \& LUZ, P.H.C. Utilização agronômica de corretivos agrícolas. Piracicaba, FEALQ, 2004. 120p. 